\title{
POISONING OBSERVATION AND ASSESSMENT
}

\author{
By \\ Prof. Dr. Naveed Shibli \\ Head Department of Psychology \\ Riphah International University Faisalabad Pakistan \\ thedailyeasyenglish@yahoo.com \\ AZRA PARVEEN \\ Clinical Psychologist \\ aizyas100@gmail.com \\ 03227702182 \\ SUNDAS RANA \\ Clinical Psychologist \\ sundasrana667@gmail.com \\ 03427865436
}

\begin{abstract}
Records of 360 poisoning patients were evolved with observation by trained experts for 6 months on a structured taxonomy sheet (STS) on first entry to a selected poisoning ward. Observations made were about the patients' appearance, facial expressions, vocal signs, social interaction and other observable signs. It was assumed that (STS) could help to distinguish between self, accidental and pretended poisoning behaviors as a quick measure as compared with existing hospital emergency diagnosis procedures. (STS) records were compared with emergency diagnosis. Comparison revealed (STS) capacity to report otherness in three poisoning types with workable similarity. Importance of observational methods emerged in high emergency for
\end{abstract}


diagnosis/ assessment that could be utilized in areas having less advanced facilities for diagnosis. Methodology suitability emerged as objective diagnosis/ assessment possibility in other kinds of emergency situations in less developed areas. More cross cultural comparison would highlight utility in developing cultures?

Key Word: Poisoning, Observation, Assessment

\section{Introduction}

Observing patients forassessment is a known technique (Cooke, Higgins \&Kidd ,2003) and valid practice (Baglio, Baxter, Guinn, Thompson, Shaffer \& Frye, 2004).Observational assessment (Kogan, Conforti, Bernabeo, Iobst\&Holmboe, 2011) is to assess behavior by observing (Horgas, Elliott \&Marsiske, 2009). Posture observations found useful in behavior assessment (JuulKristensen, Hansson, Fallentin, Andersen \&Ekdahl, 2001) however, head posture assessment showed little validity (Silva, Punt \& Johnson, 2010) but behavior studies by video recording provided useful clues about behavioral assessment (Hansen, Lambert \& Faber, 2012). At present various behavioral assessment methods (Briesch, Chafouleas\& Riley-Tillman, 2010) like observation assessment scales (Van Herk, Van Dijk, Baar, Tibboel\& De Wit, 2007) are available, a few include, Critical-Care Pain Observation Tool (CPOT) (Gélinas\& Johnston, 2007), Disruptive Behavior Diagnostic Observation Schedule (DB-DOS) (Wakschlag, Hill, Carter, Danis, Egger, Keenan, ... \& Briggs-Gowan, 2008), Standardized Direct Observation Assessment Tool (Shayne, Gallahue, Rinnert, Anderson, Hern\& Katz, 2006) and NOSGER(Spiegel, Brunner, Ermini-Fünfschilling, Monsch, Notter, Puxty\&Tremmel, 1991). Observation method has successfully been used for multipurpose assessments like clinical skill assessment (Kogan, Holmboe\&Hauer, 2009) and review of couples' observations for clinical value (Heyman, 2001). Observational assessment taxonomy ispossible (Leat\& Nichols, 2000), it add into the value of 
therapist or physician those came across situations to assess patients with observational assessment and itproved useful (Pelgrim, Kramer, Mokkink, Van den Elsen, Grol\& Van der Vleuten, 2011).

Anything that can harm life by inhaling, intake, injecting, and ingesting and absorbing can be a kind of poisoning; various substances could cause toxicity (Lynn and Christopher, 2016). Different poisoning situations exist across the cultures (Wananukul, Sriapha, Tongpoo, Sadabthammarak, Wongvisawakorn \& Kaojarern, 2007) and it is an important health problem (Mutlu, Cansu, Karakas, Kalyoncu \& Erduran, 2010).Poisoning comprehensive definition is available (Belson, Schier, Patel\& Centers for Disease Control and Prevention (2005). Poisoning is usually acute in nature (Devendranath; Mohammad,,; Mohammad; Mainnudin; Nur; Ariful,2013). It causes frequent deaths (Meel 2011: Ala, Vahdati, Moosavi\&Sadeghi, 2011). Household products identified as the main cause of poisoning in urban areas of India (Patil, Peddawad, Verma\& Gandhi, 2014). In 2011 approximately 205000 patients treated for acute poisoning in Germany, the causes reported for these cases were medical drugs, chemicals, plants, foods, or cosmetics (Müller \&Desel, 2013).

Some of poisoning substances those reported as causing poisoning in various studies include organophosphate compounds, dichlorvos, diazinon, parathion-methyl. (Yurumez, Durukan, Yavuz, Ikizceli, Avsarogullari, Ozkan,..\&Ozdemir, 2007), antidepressant drugs (24.37\%), sedative-hypnotics (19\%), tricyclic antidepressants (TCA) (14.7\%), cardiovascular drugs (11.4\%) (Jalali, Savari, Dehdardargahi \& Azarpanah, 2012), agrochemical pesticides (49\%), drugs (17\%), alcohols (13\%) (Singh \&Unnikrishnan, 2006), anxiolytic/hypnotic drugs (lorazepam), acetaminophen (Lin, Liu, Liu, Chang, Chou \& Wu, 2011), DSP, benzodiazepines (36.6\%), paracetamol (22.2\%), and antipsychotics (12.1\%) (Cheri, Ramesh, Bhakta\& Chris, 2012), 
sedative-hypnotics, opioids, pesticides organophosphates OPs (Shadnia, Esmaily, Sasanian, Pajoumand, Hassanian-Moghaddam\&Abdollahi, 2007), alcohol (54.55\%), medication (25.95\%), pesticide (5.65\%), drug (4.88\%) (Chen, Wen, Wang, Lin \& Lin, 2010), pharmaceuticals (63.1\%), alcohol and surrogates (49.3\%), and corrosives (21.8\%)(Ostapenko, Matveev, Gassimova\&Khonelid ze, 2001).

Poisoning is of various types (Trestrail 2000) and each type has its own characteristics and manifestations (Trestrail, John 2007). Risk assessment in poisoning situations is an important aspect related with intervention, the more prompt and accurate the intervention is the more safety could be exercised in an outcome (Paumgartten, Francisco 1993). The poisoning can be accidental or intentional (Chibwana, Mhango\&Molyneux 2001). A study reported that (79\%) poisoning cases were of intentional poisoning (Shadnia, Esmaily, Sasanian, Pajoumand, Hassanian-Moghaddam\&Abdollahi 2007). People use various modesfor poisoninglike by ingestion (77.8\%), given by others (16\%), suicide attempts (6.2\%)(Assar, Hatami, Lak, Pipelzadeh\&Joorabian, 2009).According to the figures mentioned in another study the causes of poisoningwere suicide attempts (35.4\%), accidents (28.4\%), ignorance (26.8\%) and occupational (8.6\%) (Chirasirisap, Ussanawarong, Tassaneeyakul, Reungsritrakool, Prasitwatanaseree, Sripanyawit,., ... \&Patitas, 1992). In another work poisoning for attempted suicide was reported as $(92 \%)$ and due to drug intoxication (90\%) (Kara, Bayir, Degirmenci, Kayis, Akinci, Ak,...\&Azap 2014). Another study found that the most (72\%) poisonings were intentional and only (27\%) were unintentional (Sahin, Carman \&Dinleyici, 2011). Belson, Schier, Patel \& Centers for Disease Control and Prevention (2005) while discussing causes of poisoning reported attempted (35.4\%), accidental (28.4\%), by ignorance (26.8\%) and due to occupation (8.6\%). Some studies are available about poisoning in animals (Xavier \&Kogika, 2002). 
Frequently observed symptoms of poisoning include nausea, vomiting, burns on the lips, blister or rashes on the skin, around the mouth, ulcers, low blood pressure, hyper ventilation, burning, palpitation, $\quad$ breathlessness, $\quad$ hypothermia, rapid heart beat, restlessness, palpitations, breathing problems, irritation in trachea or larynx or esophagus.

Prediction of suicide risk is difficult in clinical practice (Carter, Reith, Whyte \&McPHERSON, 2005), however it was found thatsuicide attempters' personality scoresless resemble with other populations (Ghanem, Gamaluddin, Mansour, Samiee', Shaker\& El Rafei, 2013)but, association between personality traits and self-poisoning have been reported (Ardani, Naghibzadeh, Hosseini, Asadpour\&Khabazianzadeh, 2015). Self-poisoning is an overdose of any substance or chemical taken for self-harm or for other reasons(Rasimas, Smolcic, \& Sinclair, 2017).Bjornaas, Teige, Hovda, Ekeberg, Heyerdahl \& Jacobsen (2010) have discussed some specific 'patterns' among the poisoning cases. Coklo, Stemberga, Cuculic, Sosa \&Bosnar, (2009) also referred some 'patterns' in various kinds of poisoning, moreover, Coklo, Stemberga, Cuculić, \&Šoša, \&Bosnar, (2009a) discussed a hypothetical relationship between kind of poisoningand modes of committing suicide.

Ala, Vahdati, Moosavi\&Sadeghi (2011) studied the role of demography regarding poisoning. It was found that medical doctors use BZD for poisoning, employed used opioids and alcoholf or poisoning as compared with unemployed, moreover males commit suicide with opioids and alcohol as compared with female those use other means. The researchers also provided useful information about age, gender, occupation and level of education. It was also found that preventable accidental poisoning still play a significant role in child morbidity (Sahin, Carman 
\&Dinleyici, 2011). Moreover the age groups affected by poisoning fall between the age group of 11-30 years of age (Chirasirisap, Ussanawarong, Tassaneeyakul, Reungsritrakool, Prasitwatanaseree, Sripanyawit,... \&Patitas, 1992).

The importance of correct and prompt diagnosis in ailment management is known (Lee, Goren, Zou, Odell, Russell, Araiza, \&Luo 2016). Objectivity in psychologicalassessment is historical (Gillham, 2001) and has contributed positively towards treatment efficiency (John 2003).A study revealed that the more objective the diagnosis would be the more feasible it would be to practice psychiatry (Pies, 2007).Therefore, objectivity is a known psychological preference for assessment (Hart \& Goldstein1986;Groth-Marnat 2009; Anastasi 1954) and psychiatry (Pies, 2007). Moreoveradvancement in clinical psychology is a continuous need (Valle \&Klimo, 2014).Furthermore,field of assessmentis improving day by day (Greene2011).In that context the shift of attention towards the healthcare provider and clients 'interaction' for better health outcomes (von Thiele 2016) is now a focused area.Hull (1937) rated observed facts about adaptive behavior important for behavior assessment. Anobservational study for poisoning cases for demographic analysis (Thapa, Lama, Karki\&Khadka, 2008) found it useful for assessment. The present study therefore was planned to explore that is it possible with a systematic objective observation to assess, label and diagnose different type of poisoning cases during initial interaction for prompt and improved intervention that may be useful for the areas where advanced medical facilities lack?

\section{Sample and Description}


All the poisoning cases those reported to the poisoning ward of a selected government hospital for admissions from January , 2017 to June, 2017 were included in the present study as sample, total number of participants was 360 those included 197males (54.7\%) 162 females (45\%) and $01(0.3 \%)$ she male. The age range of respondents was starting from 04 years and was less than 90 years of age. In age group 1 to 15 years of age the number of patients were 16.In the age group of 16 to 30 the number of patients were 260 , that was the highest percentage $73 \%$.In age group 31 to 45 years of age the number of patients were 57. The patients between age group of 46 to 60 were 21 and in age group 61 to 75 were only 1 , whereas, in age group 76 to 90 the number of patients were 2 . Among these 172(47.8\%) participants were single $180(50 \%)$ were married and $02(0.6 \%)$ were divorced whereas $06 \quad$ (1.7) were unknown with improper history. A huge number of patients were illiterate $107(29.7 \%), \quad 51 \quad(14.1 \%)$ were $\quad$ under metric, 73 (20.3\%) were matriculates and intermediate. Only $30(8.3 \%)$ were graduates whereas only 06 (1.7\%) were highly qualified. $13(3.6 \%)$ cases were having no history of education. A large number of participants were unemployed 144 out of 360, 100 out of 360 were students , 102 were employed , 01 was handicapped and 13 were with no history. Most of cases were referred by parents and a few by others. Large number of cases 161 out of 360 waited formal discharge from the ward by their doctors but about 70 cases left without informing and 89 shifted to other wards relating to their complications. 40 cases expired.

\section{Method and Procedure}


The 6 months unobtrusive study was conducted to make possible descriptive and narrative pictures of self, accidental and pretended poisoning behaviors. The running records of all poisoning patients' behaviors those admitted in the selected ward were recorded on a Structured Taxonomy Sheet (STS) (Appendices- A) by expert observers for six months. (STS) recorded observations later were compared with initial provisional medical diagnosis of the patients in the emergency and after it with final medical diagnosis. It was assumed that (STS) records could indicate differences between poisoning type behaviors close to medical diagnosis now in practice as a quick diagnostic measure for quick intervention and subsequent pre-cautionary measures? The assumption was based on the fact that for intrinsic motives/reasons the difference due to poising category could be observable or could occur in overt behaviors of the poisoning patients? The study was conducted in three phases. In the first phase (STS) was developed in which the possible "poisonous behaviors" in focused categories were described. Expert opinion was also sought during development. In the second phase research assistants were hired for 24 hours duties on the ward counters in the selected poisoning ward. All the three research assistants were familiarized with the nature of study and were apprised about the hand ling and filling of (STS).Demos and practicing sessions were conducted to fully equip the assistants to meet the requirements of the job.After confirmation that the hired persons had achieved the requisite skills the third phase of study was started in which research assistants were assigned to complete (STS) for six months in the ward as trained.

Riphah Research Ethics Committee approved the study. For verbal inform consent, following instructions were delivered to the research assistants before the conduct. "Watch each admission in the ward on first entrance. Fill in (STS) columns with complete details of first exposure. Do not leave any column blank and in case some other behavior/s takes place that were not 
mentioned in (STS) than record it/these as a separate note. After recording the response when you (researcher) found that the patient is settled than approach the patient. If patient in not in senses approach caregiver of the patient for the permission to retain the (STS) recorded response for research purpose. Show the recorded response to the patient or caregiver. Get the permission for inclusion, if patient or caregiver accord approval then include (STS) in the records otherwise delete and count the mentioned number in the study as deleted. During the entire study the data collectors followed the instructions in letter and spirit and a verbal informed consent for each case was acquired.

A few glimpses of details filled in the (STS) were.

- Mode of entrance in poisoning unit as: walking, walking with help, wheel chair, use stature and a few other details.

- Appearance including height, weight, any peculiar feature, hair, dress and a few more.

- Facial Expressions including color of the face, sweating, oral secretions and some more.

- Vocal signs including crying, weeping, scolding, cursing, mute and other details.

- Social interaction and mode details.

- Other signs like breathing, eye movement, and heart rate and a few others.

After the completion of third phase the data gathered by experts was compared with provisional medical diagnosis and final medical diagnosis records of all the casesto assess the comparability of (STS)with already in practice diagnosis methods. 


\section{Results}

Among total 360 studied poisoning patients 35, 9.7\% were of pretended poisoning, 236, 65.6\% wereself-poisoning and 89, 24.7\% wereaccidental poisoning. The patterns on (STS) were found closely similar to final medical diagnosis as compared with provisional medical diagnosis. The occurrence of particular behaviors in particular poisoning category (Figure-A)/, (Table-A) were visible and sufficient to support 'patterns' for particular category. The assessment of different types of poisoning casespossibility for intervention based on systematic objective observation (STS) supported.

\section{Conclusion/ Discussion}

Diagnosing patterns of three types of poisoning behaviors pretended, self and accidental bysystematic objective observation with (STS) method is possible. For cross cultural applications fresh studies catering for various cultural needs are recommended to test (STS) method utility for quickpoisoning type diagnosis.(STS) however application even in similar cultural context may not be practiced without caution and required medical assistance. The studysuccessfully highlights the importance of systematic observation in clinical assessment. Importance of observational methods emerged in high emergency cases for diagnosis/ assessment. It could be utilized in the areas where less advanced diagnostic facilities necessary for modern diagnosis are available. It is easy, could be used without much expertize and even by a nonprofessional. The proposed method in the study could be utilized in other emergencies situations if developed in similar way, the study thereby, brought in a possibility for objective evaluation/ assessment/diagnosis in medical situations in the developing world to cater for less modern medical facilities available there. 


\section{References}

Ala, A., Vahdati, S. S., Moosavi, L., \&Sadeghi, H. (2011). Studying the Relationship Between Age, Gender and Other Demographic Factors with the Type of Agent Used for Self-Poisoning at $\begin{array}{lllll}\text { a Poisoning } & \text { Referral } & \text { Center } & \text { in }\end{array}$ Iran/KuzeyBatiIran'daBirZehirlenmeReferansMerkezindeKendiniZehirlemekiçinKullanilanAjan Tipi ileYas, CinsiyetveDigerDemografikFaktörlerinIliskisininArastirilmasi. Journal of Academic Emergency Medicine, 10(3), 100.

Anastasi, A. (1954). Psychological testing.

Ardani, A. R., Naghibzadeh, B., Hosseini, F. F., Asadpour, Z., \&Khabazianzadeh, F. (2015).Temperament and character personality profile and affective temperaments in selfpoisoning nonlethal suicide attempters. Psychiatry research, 229(1-2), 394-400.

Assar, S., Hatami, S., Lak, E., Pipelzadeh, M., \&Joorabian, M. (2009).Acute poisoning in children. Pak J Med Sci, 25(1), 51-54.

Baglio, M. L., Baxter, S. D., Guinn, C. H., Thompson, W. O., Shaffer, N. M., \& Frye, F. H. (2004). Assessment of interobserver reliability in nutrition studies that use direct observation of school meals. Journal of the American Dietetic Association, 104(9), 1385-1392.

Belson, M. G., Schier, J. G., Patel, M. M., \& Centers for Disease Control and Prevention. (2005). Case definitions for chemical poisoning.National Emergency Training Center.

Bjornaas, M. A., Teige, B., Hovda, K. E., Ekeberg, O., Heyerdahl, F., \& Jacobsen, D. (2010). Fatal poisonings in Oslo: a one-year observational study. BMC emergency medicine, 10(1), 13. 
Briesch, A. M., Chafouleas, S. M., \& Riley-Tillman, T. C. (2010). Generalizability and dependability of behavior assessment methods to estimate academic engagement: A comparison of systematic direct observation and direct behavior rating. School Psychology Review, 39(3).

Carter, G., Reith, D. M., Whyte, I. M., \&McPHERSON, M. I. C. H. E. L. L. E. (2005).Repeated self-poisoning: increasing severity of self-harm as a predictor of subsequent suicide. The British Journal of Psychiatry, 186(3), 253-257.

Chen, F., Wen, J. P., Wang, X. P., Lin, Q. M., \& Lin, C. J. (2010). Epidemiology and characteristics of acute poisoning treated at an emergency center. World journal of emergency medicine, 1(2), 154.

Chibwana, C., Mhango, T., \&Molyneux, E. M. (2001).Childhood poisoning at the Queen Elizabeth Central Hospital, Blantyre, Malawi. East African medical journal, 78(6), 292-295.

Chirasirisap, K., Ussanawarong, S., Tassaneeyakul, W., Reungsritrakool, W., Prasitwatanaseree, W., Sripanyawit, U., ...\&Patitas, N. (1992). A study of major causes and types of poisoning in Khonkaen, Thailand. Veterinary and human toxicology, 34(6), 489-492.

Churi, S., Ramesh, M., Bhakta, K., \& Chris, J. (2012).Prospective assessment of patterns, severity and clinical outcome of Indian poisoning incidents. Chemical and Pharmaceutical Bulletin, 60(7), 859-864.

Coklo, M., Stemberga, V., Cuculic, D., Sosa, I., \&Bosnar, A. (2009). Toxicology and methods of committing suicide other than overdose. Medical hypotheses, 73(5), 809-810. 
Coklo, Miran\&Stemberga, Valter\&Cuculić, Drazen\&Šoša, Ivan \&Bosnar, Alan.(2009a). Toxicology and methods of committing suicide other than overdose. Medical hypotheses. 73. 809-10. 10.1016/j.mehy.2009.03.047.

Cooke, M. W., Higgins, J., \& Kidd, P. (2003). Use of emergency observation and assessment wards: a systematic literature review. Emergency Medicine Journal, 20(2), 138-142.

DevendranathSarkar; Mohammad Shaheduzzaman,,; Mohammad Ismail Hossain; Mainnudin Ahmed; Nur Mohammad; Ariful Basher (March 2013). "Spectrum of Acute Pharmaceutical and Chemical Poisoning in Northern Bangladesh"ASIA PACIFIC JOURNAL of MEDICAL TOXICOLOGY APJMT2;1 http://apjmt.mums.ac.ir MARCH 2013

Gélinas, C., \& Johnston, C. (2007). Pain assessment in the critically ill ventilated adult: validation of the Critical-Care Pain Observation Tool and physiologic indicators. The Clinical journal of pain, 23(6), 497-505.

Ghanem, M., Gamaluddin, H., Mansour, M., Samiee', A. A., Shaker, N. M., \& El Rafei, H. (2013).Role of impulsivity and other personality dimensions in attempted suicide with selfpoisoning among children and adolescents. Archives of suicide research, 17(3), 262-274.

Gillham, Nicholas W. (2001). "Sir Francis Galton and the birth of eugenics". Annual Review of Genetics. 35 (1): 83-101.

Greene, R. L. (2011). Some considerations for enhancing psychological assessment. Journal of personality assessment, 93(3), 198-203.

Groth-Marnat, G. (2009). Handbook of psychological assessment.John Wiley \& Sons. 
Hansen, T., Lambert, H. C., \& Faber, J. (2012).Reliability of the Danish version of the McGill Ingestive Skills Assessment for observation-based measures during meals. Scandinavian journal of occupational therapy, 19(6), 488-496.

Hart, R. R., \& Goldstein, M. A. (1986).Computer-assisted psychological assessment. Computers in Human Services, 1(3), 69-75.

Heyman, R. E. (2001). Observation of couple conflicts: Clinical assessment applications, stubborn truths, and shaky found ations. Psychological assessment, 13(1), 5.

Horgas, A. L., Elliott, A. F., \&Marsiske, M. (2009). Pain assessment in persons with dementia: Relationship between self-report and behavioral observation. Journal of the American Geriatrics Society, 57(1), 126-132.

Hull, C. L. (1937). Mind, mechanism, and adaptive behavior. Psychological Review, 44(1), 1-32. http://dx.d oi.org/10.1037/h0058294

Kay, A. C., Whitson, J. A., Gaucher, D., \&Galinsky, A. D. (2009). Compensatory control: Achieving order through the mind, our institutions, and the heavens. Current Directions in Psychological Science, 18(5), 264-268.

Kogan, J. R., Conforti, L., Bernabeo, E., Iobst, W., \&Holmboe, E. (2011).Opening the black box of clinical skills assessment via observation: a conceptual model. Medical education, 45(10), 1048-1060.

Jalali, A., Savari, M., Dehdardargahi, S., \&Azarpanah, A. (2012). The pattern of poisoning in southwestern region of Iran: envenoming as the major cause. Jundishapur journal of natural pharmaceutical products, 7(3), 100. 
John D., Wasserman (2003). "Nonverbal Assessment of Personality and Psychopathology".In McCallum, Steve R. Handbook of Nonverbal Assessment. New York: Kluwer Academic / Plenum Publisherstesting

Juul-Kristensen, B., Hansson, G. Å., Fallentin, N., Andersen, J. H., \&Ekdahl, C. (2001).Assessment of work postures and movements using a video-based observation method and direct technical measurements. Applied ergonomics, 32(5), 517-524.

Kara, H., Bayir, A., Degirmenci, S., Kayis, S. A., Akinci, M., Ak, A., ..\&Azap, M. (2014). Causes of poisoning in patients evaluated in a hospital emergency department in Konya, Turkey. J Pak Med Assoc, 64(9), 1042-1048.

Kogan, J. R., Holmboe, E. S., \&Hauer, K. E. (2009). Tools for direct observation and assessment of clinical skills of medical trainees: a systematic review. Jama, 302(12), 1316-1326.

Leat, D., \& Nichols, A. (2000). Brains on the table: Diagnostic and formative assessment through observation. Assessment in Education: Principles, Policy \& Practice, 7(1), 103-121.

Lee, L. K., Goren, A., Zou, K. H., Odell, K., Russell, D., Araiza, A. L., \&Luo, X. (2016).Potential benefits of diagnosis and treatment on health outcomes among elderly people with symptoms of overactive bladder. International journal of clinical practice, 70(1), 66-81.

Lin, Y. R., Liu, T. H., Liu, T. A., Chang, Y. J., Chou, C. C., \& Wu, H. P. (2011). Pharmaceutical poisoning exposure and outcome analysis in children admitted to the pediatric emergency department. Pediatrics \& Neonatology, 52(1), 11-17. 
Lynn S McCarty yz and Christopher J Borgertz y LSARE (2016) ALL CURRENT ECOTOXICITY TEST RESULTS CONFOUNDED BY DESIGN AND IMPLEMENTATION ISSUES?Integrated Environmental Assessment and Management 12(2)

Meel, B. L. (2011). Aluminium phosphide (tank pill) poisoning in the Transkei region of South Africa: a case report. Medicine, Science and the Law, 51(2), 116-118.

Müller, D., \&Desel, H. (2013). Common causes of poisoning: etiology, diagnosis and treatment. DeutschesÄrzteblatt International, 110(41), 690.

Mutlu, M., Cansu, A., Karakas, T., Kalyoncu, M., \&Erduran, E. (2010). Pattern of pediatric poisoning in the east Karadeniz region between 2002 and 2006: increased suicide poisoning. Human \& experimental toxicology, 29(2), 131-136.

Ostapenko, Y. N., Matveev, S. B., Gassimova, Z. M., \&Khonelidze, R. S. (2001).Epidemiology and medical aid at acute poisoning in Russia. Przegladlekarski, 58(4), 293-296.

Paumgartten, Francisco J. R.. (1993). Risk assessment for chemical substances: the link between toxicology and public health. Cadernos de SaúdePública, 9(4), 439447. https://dx.doi.org/10.1590/S0102-311X1993000400004

Patil, A., Peddawad, R., Verma, V. C. S., \& Gandhi, H. (2014). Profile of acute poisoning cases treated in a tertiary care hospital: a Study in Navi Mumbai. Asia Pacific Journal of Medical Toxicology, 3(1), 36-40.

Paumgartten, Francisco J. R.. (1993). Risk assessment for chemical substances: the link between toxicology and public health. Cadernos de SaúdePública, 9(4), 439447. https://dx.doi.org/10.1590/S0102-311X1993000400004 
Pelgrim, E. A., Kramer, A. W. M., Mokkink, H. G., Van den Elsen, L., Grol, R. P. T. M., \& Van der Vleuten, C. P. M. (2011). In-training assessment using direct observation of single-patient encounters: a literature review. Advances in health sciences education, 16(1), 131-142.

Pies, R. (2007). How “objective" are psychiatric diagnoses?:(guess again). Psychiatry (Edgmont), 4(10), 18.

Rasimas, J. J., Smolcic, E. E., \& Sinclair, C. M. (2017). Themes and Trends in Intentional SelfPoisoning: Perspectives from Critical Care Toxicology. Psychiatry Research.

Shadnia, S., Esmaily, H., Sasanian, G., Pajoumand, A., Hassanian-Moghaddam, H., \&Abdollahi, M. (2007).Pattern of acute poisoning in Tehran-Iran in 2003. Human \& experimental toxicology, 26(9), 753-756.

Sahin, S., Carman, K. B., \&Dinleyici, E. C. (2011).Acute poisoning in children; data of a pediatric emergency unit. Iranian journal of pediatrics, 21(4), 479.

Shayne, P., Gallahue, F., Rinnert, S., Anderson, C. L., Hern, G., \& Katz, E. (2006). Reliability of a core competency checklist assessment in the emergency department: the Standardized Direct Observation Assessment Tool. Academic Emergency Medicine, 13(7), 727-732.

Silva, A. G., Punt, T. D., \& Johnson, M. I. (2010). Reliability and validity of head posture assessment by observation and a four-category scale. Manual therapy, 15(5), 490-495.

Singh, B., \&Unnikrishnan, B. (2006).A profile of acute poisoning at Mangalore (South India). Journal of clinical forensic medicine, 13(3), 112-116.

Spiegel, R., Brunner, C., Ermini-Fünfschilling, D., Monsch, A., Notter, M., Puxty, J., \&Tremmel, L. (1991). A new behavioral assessment scale for geriatric out-and in-patients: the 
NOSGER (Nurses' Observation Scale for Geriatric Patients). Journal of the American Geriatrics Society, 39(4), 339-347.

Trestrail J.H. (2000) Types of Poisons. In: Criminal Poisoning. Forensic Science and Medicine. Humana Press, Totowa, NJ

Trestrail, III, John H. (2007)Criminal Poisoning: Investigational Guide for Law Enforcement, Toxicologists...Hamana Press Inc. 999 Riverview Drive Suite 208 Totawa New Jersey

Thapa, S. R., Lama, P., Karki, N., \&Khadka, S. B. (2008).Pattern of poisoning cases in Emergency Department of Kathmandu Medical College Teaching Hospital. Kathmandu University medical journal (KUMJ), 6(2), 209-213.

Valle, R., \&Klimo, J. (2014). The Evolution of Psychological Testing: Embarking on the Age of Digital Assessment

Van Herk, R., Van Dijk, M., Baar, F. P., Tibboel, D., \& De Wit, R. (2007). Observation scales for pain assessment in older adults with cognitive impairments or communication difficulties. Nursing Research, 56(1), 34-43.

von Thiele Schwarz, U. (2016). Co-care: Producing better health outcome through interactions between patients, care providers and information and communication technology. Health services management research, 29(1-2), 10-15.

Wakschlag, L. S., Hill, C., Carter, A. S., Danis, B., Egger, H. L., Keenan, K., ...\& BriggsGowan, M. J. (2008). Observational assessment of preschool disruptive behavior, part I: reliability of the Disruptive Behavior Diagnostic Observation Schedule (DB-DOS). Journal of the American Academy of Child \& Adolescent Psychiatry, 47(6), 622-631. 
Wananukul, W., Sriapha, C., Tongpoo, A., Sadabthammarak, U., Wongvisawakorn, S., \&Kaojarern, S. (2007). Human poisoning in Thailand: the Ramathibodi Poison Center's experience (2001-2004). Clinical toxicology, 45(5), 582-588.

Xavier, F. G., \&Kogika, M. M. (2002).Common causes of poisoning in dogs and cats in a Brazilian veterinary teaching hospital from 1998 to 2000. Veterinary and human toxicology, 44(2), 115-116.

Yurumez, Y., Durukan, P., Yavuz, Y., Ikizceli, I., Avsarogullari, L., Ozkan, S., ...\&Ozdemir, C. (2007). Acute organophosphate poisoning in university hospital emergency room patients. Internal medicine, 46(13), 965-969.

\section{Appendices- A}

\section{Structured Taxonomy Chart (STS)}

Form to record possible self, accidental and pretended, poisoning taxonomy in poisoning unit

(To be filled by the researcher as he/she observes on the first entrance and exposure of the admitted patient)

Personals and Official details

Age/ Sex: Hospital no:Marital status:Qualification:Occupation:

Referred by: Address: $\quad$ Date of Admission: Date of Disease, Death, etc

Encircle the appropriate on the first exposure entrance of the patient in the ward

1- Mode of entrance in the ward: 
a- Was walking b- Walking with support c- On wheelchair d- On stature e- Resisting to the attendant to be admitted in hospital

\section{2- First contact with the ward:}

a- Looked toward attendant b- Looked toward Nurse/Doctor c- Was Semi conscious dUnconscious e- Didn't make any response

\section{3- Nurse Patient Interaction Found:}

a- Realistic b- Confused c- Convincing d-Social e- Pretending

\section{4- Appearance:}

a- Good looking b- Informal dressing c- Reflecting a dirty look d- Was half naked e- Completely naked

\section{5- Hair style:}

a- Stylish b- Partially set c- Unusual d-Dirty with dust e- Dirty with secretion

6- Vomiting and oral secretions:

a- Vomitingb- Nauseac- Watery fluidd- Thick oral secretione- Bloody secretion from mouth and nose

\section{7-Seeking help:}


a- Crying b-Weeping c- Noise excessively d-Calling names e- Laughing

8-Observable behavior:

a- Extremely fearful b- Trembling c- Death feelings d-Was sticking to the attendant

e- Cool and calm

\section{9- In case of Female:}

a- Makeup exceptional b- Usual healthy look c- Unusual d- No makeup e- Show unhealthy

\section{0- Unique symptoms:}

$\begin{array}{llll}\text { Breathing } & \text { a-Normal } & \text { b-Rapid } & \text { c-Slow deep } \\ \text { Tongue } & \text { a-Normal } & \text { b-Dry } & \text { c-Bite or any ulcer } \\ \text { Nails } & \text { a-Normal } & \text { b-Blue } & \text { c-Used nail paint } \\ \text { Eyes } & \text { a-Normal } & \text { b-Pinch forcibly } & \text { c- Pupil dilated }\end{array}$

Remarks:

Diagnosis:

Type of poison: Note: This column shall be filled when the diagnosis shall finally be finalized

(Please mark A--- for Self Poisoning, B---- for accidental Poisoning and C--- for pretended, after the final diagnostic findings are finalized)

Table-A

POISONING OBSERVATION AND ASSESSMENT 


\begin{tabular}{|c|c|c|c|c|c|}
\hline & & Pretended & Self & Accidental & Total \\
\hline \multirow{5}{*}{$\begin{array}{l}\text { The entrance } \\
\text { mode in the } \\
\text { ward } \\
\text { subdivided }\end{array}$} & was walking & 1 & 12 & 10 & 23 \\
\hline & walking with support & 22 & 29 & 11 & 62 \\
\hline & on wheelchair & 6 & 64 & 26 & 96 \\
\hline & on stature & 3 & 128 & 43 & 174 \\
\hline & resisting to the attended & 3 & 2 & 0 & 5 \\
\hline \multirow{5}{*}{$\begin{array}{l}\text { First contact } \\
\text { with the ward } \\
\text { categories were }\end{array}$} & look toward attendant & 17 & 29 & 9 & 55 \\
\hline & look toward nurse/doctor & 14 & 68 & 41 & 123 \\
\hline & semi-conscious & 0 & 69 & 26 & 95 \\
\hline & unconscious & 0 & 61 & 10 & 71 \\
\hline & didn't response & 4 & 8 & 3 & 15 \\
\hline \multirow{5}{*}{$\begin{array}{c}\text { the nurse } \\
\text { patient first } \\
\text { interaction } \\
\text { mode categories }\end{array}$} & realistic & 0 & 46 & 25 & 71 \\
\hline & confused & 9 & 83 & 36 & 128 \\
\hline & convincing & 1 & 21 & 5 & 27 \\
\hline & social & 1 & 17 & 13 & 31 \\
\hline & pretending & 23 & 8 & 2 & 33 \\
\hline \multirow{5}{*}{$\begin{array}{l}\text { appearance } \\
\text { including }\end{array}$} & good looking & 7 & 11 & 11 & 29 \\
\hline & informal dressing & 27 & 90 & 46 & 163 \\
\hline & reflecting a dirty look & 1 & 80 & 23 & 104 \\
\hline & half necked & 0 & 48 & 9 & 57 \\
\hline & completely necked & 0 & 5 & 1 & 6 \\
\hline \multirow{5}{*}{$\begin{array}{l}\text { Hair style } \\
\text { category }\end{array}$} & stylish & 13 & 5 & 10 & 28 \\
\hline & partially set & 29 & 91 & 48 & 168 \\
\hline & unusual & 2 & 32 & 12 & 46 \\
\hline & dirty with dust & 0 & 24 & 5 & 29 \\
\hline & dirty with secretion & 0 & 81 & 15 & 96 \\
\hline \multirow{5}{*}{$\begin{array}{l}\text { vomiting and } \\
\text { oral secretions }\end{array}$} & vomiting & 4 & 71 & 31 & 106 \\
\hline & nausea & 10 & 44 & 31 & 85 \\
\hline & water fluid & 0 & 17 & 2 & 19 \\
\hline & thick oral secretion & 0 & 71 & 16 & 87 \\
\hline & bloody secretion & 0 & 13 & 4 & 17 \\
\hline \multirow{5}{*}{$\begin{array}{c}\text { category } \\
\text { seeking help }\end{array}$} & crying & 17 & 76 & 29 & 122 \\
\hline & weeping & 9 & 83 & 16 & 108 \\
\hline & making noise excessively & 1 & 43 & 13 & 57 \\
\hline & calling names & 5 & 10 & 23 & 38 \\
\hline & laughing & 2 & 5 & 4 & 11 \\
\hline \multirow{3}{*}{$\begin{array}{c}\text { observable } \\
\text { behavior }\end{array}$} & extremely fearful & 2 & 46 & 36 & 84 \\
\hline & trembling & 7 & 71 & 16 & 94 \\
\hline & death feeling & 0 & 26 & 10 & 36 \\
\hline
\end{tabular}




\begin{tabular}{|c|c|c|c|c|c|}
\hline & sticking to the attendant' & 15 & 19 & 3 & 37 \\
\hline & cool and calm & 4 & 16 & 14 & 34 \\
\hline \multirow{5}{*}{$\begin{array}{c}\text { only female } \\
\text { include }\end{array}$} & make up exceptional & 1 & 3 & 5 & 9 \\
\hline & usual healthy look & 10 & 26 & 12 & 48 \\
\hline & unusual & 0 & 23 & 6 & 29 \\
\hline & no makeup & 6 & 32 & 9 & 47 \\
\hline & unhealthy & 0 & 32 & 7 & 39 \\
\hline \multirow{3}{*}{$\begin{array}{l}\text { unique symptoms } \\
\text { there were four } \\
\text { subcategories those } \\
\text { include, breathing, } \\
\text { tongue, nails and } \\
\text { eyes, in the } \\
\text { breathing the sub- } \\
\text { sub categories } \\
\end{array}$} & normal & 21 & 33 & 24 & 78 \\
\hline & rapid & 14 & 127 & 52 & 193 \\
\hline & slow deep & 0 & 68 & 12 & 80 \\
\hline \multirow{3}{*}{$\begin{array}{l}\text { in tongue } \\
\text { category }\end{array}$} & normal & 35 & 64 & 35 & 134 \\
\hline & dry & 0 & 113 & 46 & 159 \\
\hline & bite or any ulcer & 0 & 51 & 7 & 58 \\
\hline \multirow{3}{*}{$\begin{array}{l}\text { In nails } \\
\text { category }\end{array}$} & normal & 33 & 142 & 70 & 245 \\
\hline & blue & 0 & 83 & 17 & 100 \\
\hline & used nail paint & 2 & 8 & 1 & 11 \\
\hline \multirow{3}{*}{$\begin{array}{l}\text { In the eyes } \\
\text { category }\end{array}$} & normal & 31 & 142 & 63 & 236 \\
\hline & pinch forcibly & 4 & 8 & 0 & 12 \\
\hline & pupil dilated & 0 & 82 & 27 & 109 \\
\hline
\end{tabular}

(Figure-A)

POISONING OBSERVATION AND ASSESSMENT 

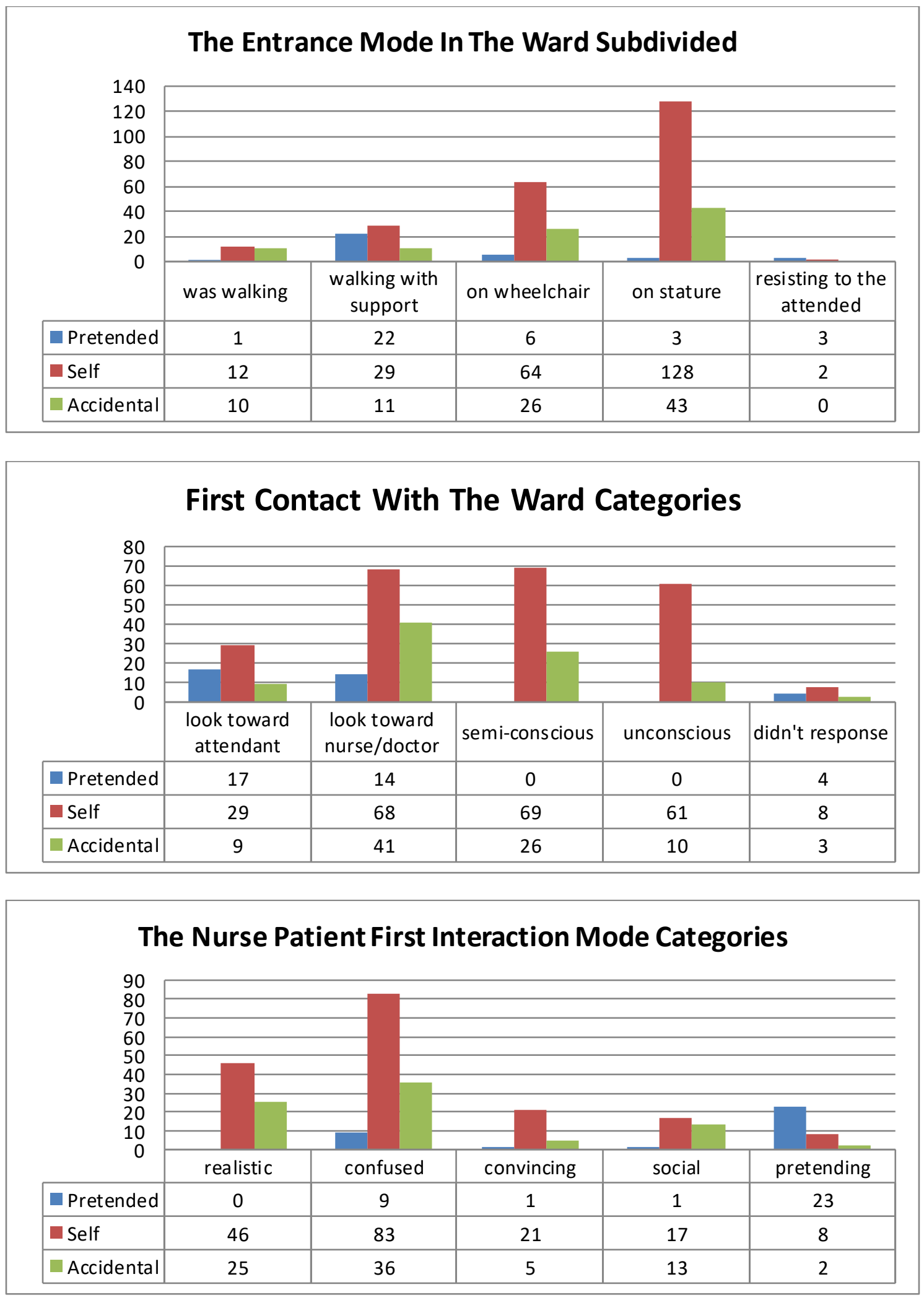

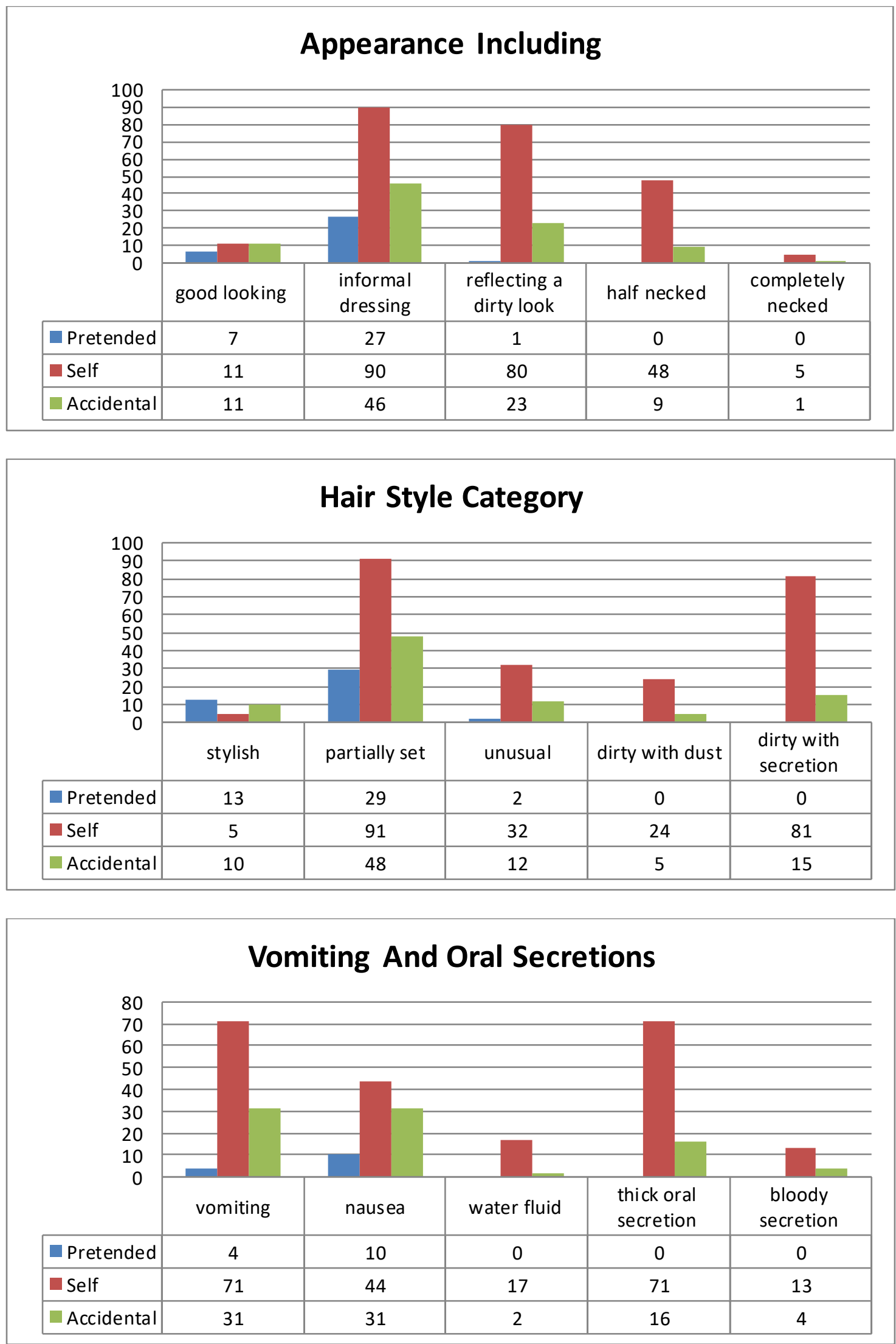

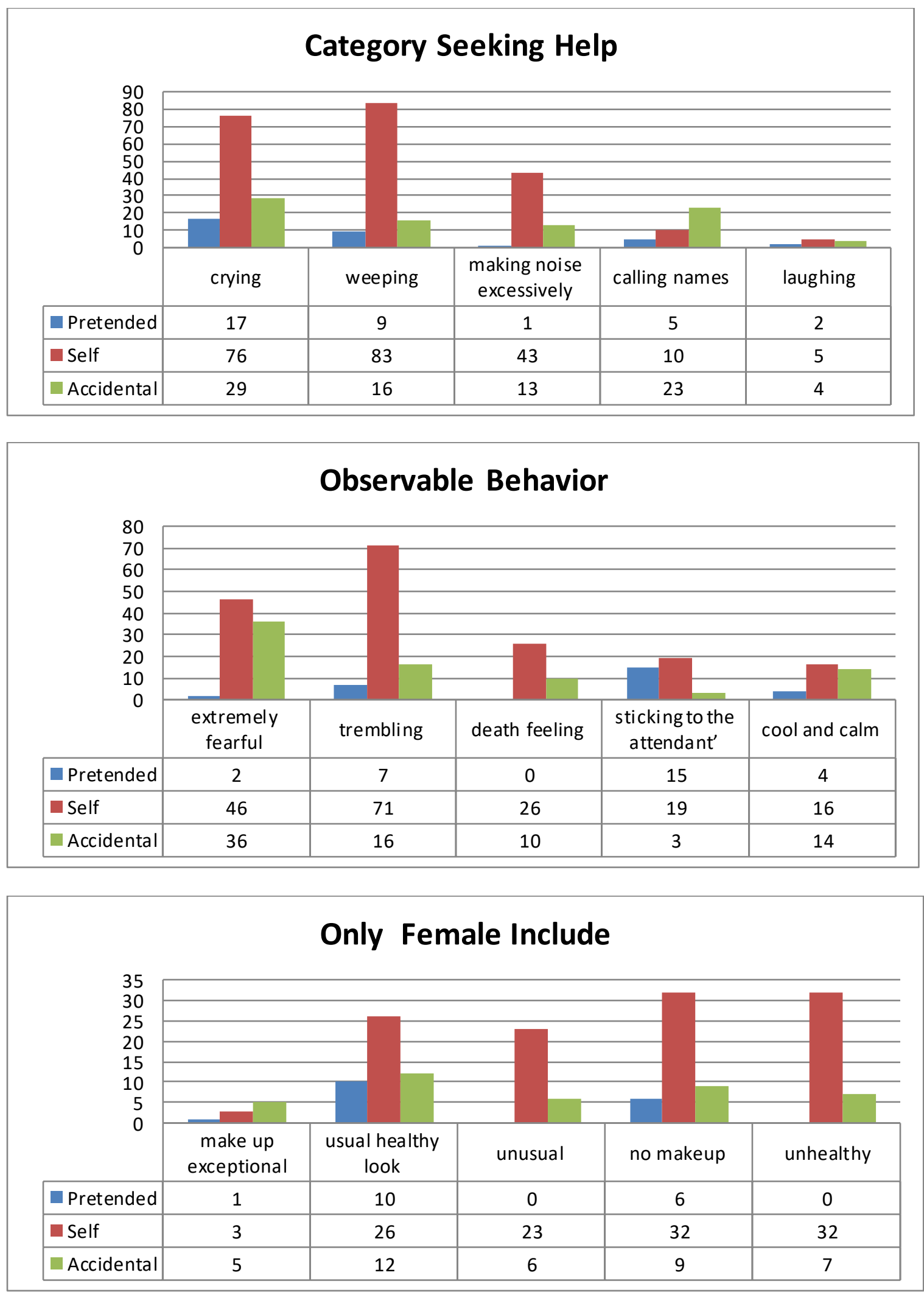

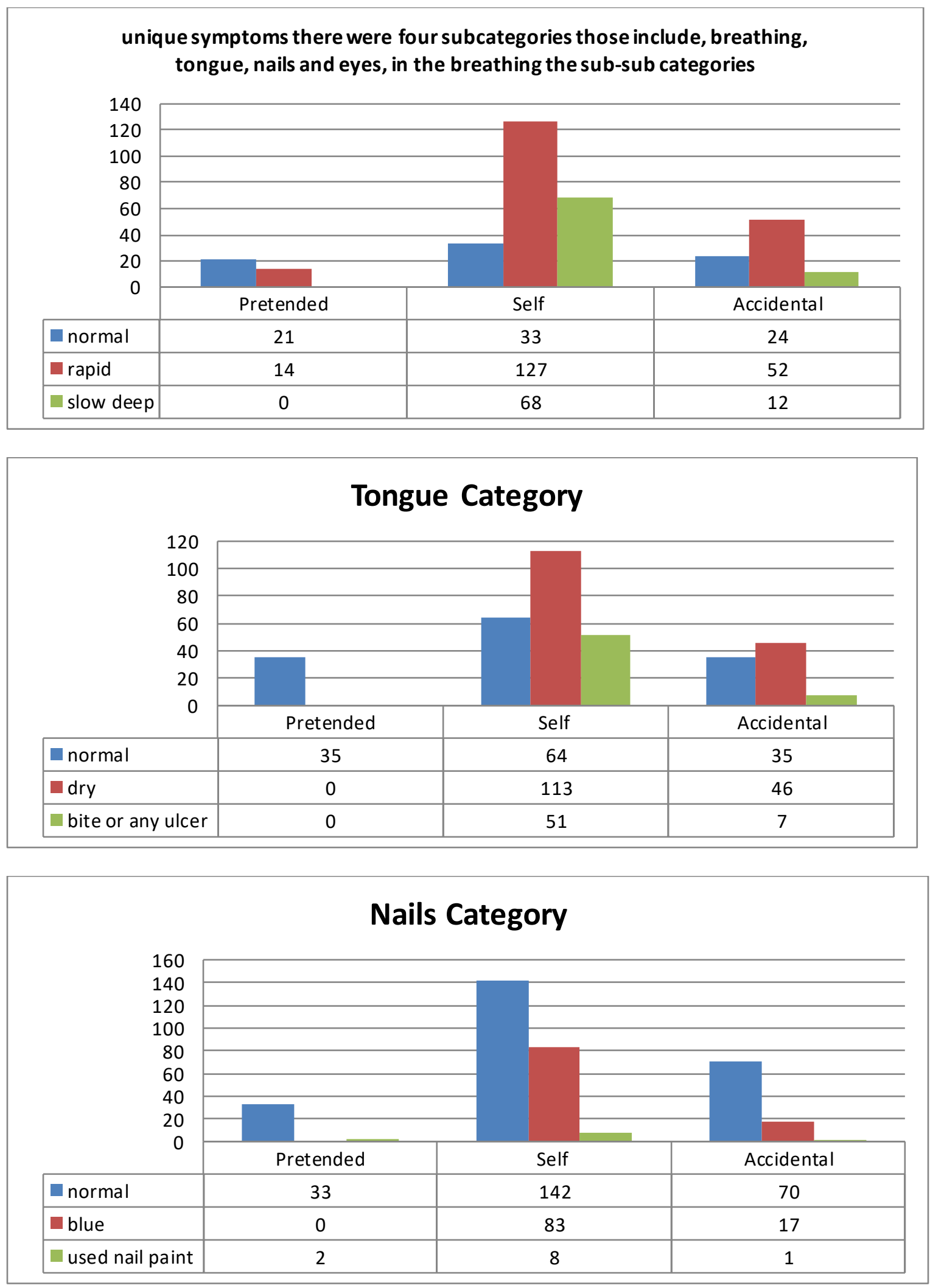


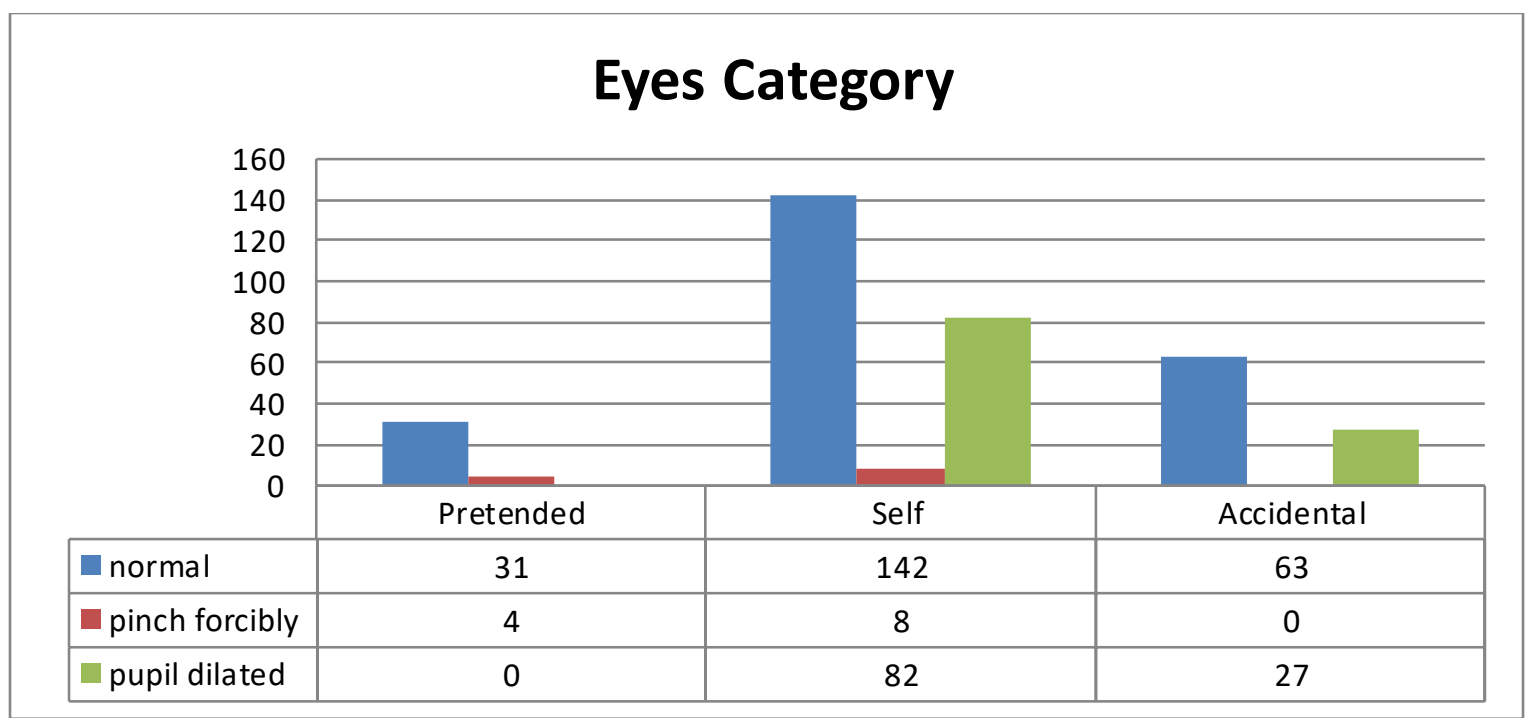

